\title{
SUPPLEMENTARYMATERIAL
}

\section{A New Anti-proliferative Acylated Flavonol Glycoside from Fuzhuan Brick-Tea}

\author{
Yong-Zhen Tian ${ }^{\mathrm{a}, \uparrow}$, Xiao Liu $^{\mathrm{a}, \uparrow}$, Wen Liu ${ }^{\mathrm{b}, \uparrow}$ Wei-Yun Wang ${ }^{\mathrm{b}}$, Yan-Hua Long ${ }^{\mathrm{b}}$, Liang Zhang ${ }^{\mathrm{a}}$, Yan Xu ${ }^{\mathrm{a}}$, Guan-Hu Bao ${ }^{\mathrm{a}}$, Xiao- \\ Chun Wan ${ }^{\mathrm{a}}$ and Tie-Jun Ling ${ }^{\mathrm{a}, *}$ \\ ${ }^{a}$ State Key Laboratory of Tea Plant Biology and Utilization, Anhui Agricultural University, 130 West Changjiang Rd., Hefei, \\ Anhui Province, PR China \\ ${ }^{b}$ School of Life Sciences, Anhui Agricultural University, 130 West Changjiang Rd. Hefei 230036, \\ P. R. China
}

\section{Address for correspondence}

Tiejun Ling, Ph. D. State Key Laboratory of Tea Plant Biology and Utilization, Anhui Agricultural University, 130 West Changjiang Rd., Hefei, Anhui Province, PR China. E-Mail address: lingtj@ahau.edu.cn, Tel: 86-551-65786401, Fax: 86-55165786765 .

\begin{abstract}
:
Fuzhuan Brick-tea (FBT) is unique for a fungal fermentation stage in its manufacture process and is classified in dark tea. A new acylated flavonol glycoside, kaempferol 3-O-[E-p-coumaroyl- $(\rightarrow 2)][\alpha-\mathrm{L}-$ arabinopyranosyl-( $(1 \rightarrow 3)][\alpha$-L-rhamnopyranosyl $(1 \rightarrow 6)]-\beta$-D-glucopyranoside, which was trivially named as camellikaempferoside A (1), was isolated from the Fuzhuan brick-tea along with camelliquercetiside C (2). Their structures were unambiguously elucidated by combination of spectroscopic and chemical methods. Compound 1 showed anti-proliferative activity against MCF-7 and MDA-MB-231 cells with $\mathrm{IC}_{50}$ values of $7.83 \mu \mathrm{M}$ and $19.16 \mu \mathrm{M}$, respectively.
\end{abstract}

\section{Keywords:}

Fuzhuan brick-tea; dark tea; camellikaempferoside A; anti-proliferative activity; MCF-7 cells; MDA-MB231 cells 


\section{List of supplementary materials}

Experimental

HPLC analysis of Some FGs in FBT

Figure S1: UV spectrum of 1

Figure S2: IR spectrum of 1

Figure S3: Optical rotation of 1

Figure S4: HRESI-MS spectrum of 1

Figure S5: ${ }^{1} \mathrm{H}-\mathrm{NMR}$ of 1 (in Methanol- $d_{4}$ )

Figure S6: ${ }^{13} \mathrm{C}-\mathrm{NMR}$ of 1 (in Methanol- $d_{4}$ )

Figure S7: ${ }^{1} \mathrm{H}-{ }^{1} \mathrm{H}$ COSY of 1 (in Methanol- $d_{4}$ )

Figure S8: HSQC of 1 (in Methanol- $d_{4}$ )

Figure S9: HMBC of 1 (in Methanol- $d_{4}$ )

Figure S10: NOESY of 1 (in Methanol- $d_{4}$ )

Figure S11: GC spectral comparison of the sugar units

Figure S12: HPLC (350 nm) analysis for 1-10, as well as UF-1 to UF-28 in BFFT and AFFT

Figure S13: UV spectra of UF-1 to UF-28 in HPLC

Figure S14: UV spectra of the chromatography peaks $\left(t_{\mathrm{R}} 43.096\right)$ in HPLC of $\mathbf{1}$, AFFT and BFFT

Figure S15: HPLC (350 nm) of the BFFT, AFFT and standard compounds 1-10

Figure S16: Quantitation analysis of 2-10 in BFFT and AFFT

Table S1: NMR data of $\mathbf{1}$ and partial ${ }^{13} \mathrm{C}$ NMR data of 2

Table S2: Linear calibration information for 2-10

Table S3: Precision, repeatability and stability of 2-10

Table S4: Recoveries of 2-10

Table S5: The contents of 2-10 in BFFT and AFFT 


\section{Experimental}

\section{General}

UV spectrum was obtained with a U-5100 spectrophotometer (Hitachi, Japan). IR spectrum was obtained with an iS50 FI-IR spectrometer (Thermo, the USA). Optical rotation was measured on a P-1020 Polarimeter (Jasco, Tokyo, Japan). ${ }^{1} \mathrm{H}$ and ${ }^{13} \mathrm{C}$ NMR, ${ }^{1} \mathrm{H}-{ }^{1} \mathrm{H}$ COSY, HSQC, HMBC and ROESY spectra were recorded with Bruker AM-400 spectrometers operating at $400 \mathrm{MHz}$ for ${ }^{1} \mathrm{H}$, and $100 \mathrm{MHz}$ for ${ }^{13} \mathrm{C}$. Coupling constants were expressed in $\mathrm{Hz}$ and chemical shifts were given on a $\delta(\mathrm{ppm})$ scale with TMS as an internal standard. The HRESI-MS was obtained with a Thermo LTQ Orbitrap XL LC-MS system by direct inlet. The GC-MS analysis was conducted on a GCMSQP2010S (Shimadzu, Japan) with DB-5MS column (30 m $\times 0.25 \mu \mathrm{m}$ i.d., Agilent Technologies, the USA), using the following conditions: injection temperature at $280{ }^{\circ} \mathrm{C}$, initial temperature was 160 ${ }^{\circ} \mathrm{C}$ for $1 \mathrm{~min}$, then raised to $200^{\circ} \mathrm{C}$ at $6{ }^{\circ} \mathrm{C} / \mathrm{min}$, and further raised to $280{ }^{\circ} \mathrm{C}$ at $3{ }^{\circ} \mathrm{C} / \mathrm{min}$, final temperature kept for $5 \mathrm{~min}$. HPLC analyses were performed on a Waters Alliance 2695 HPLC system equipped with a binary solvent manager, sample manager, column heating compartment, photodiode array (PDA) detector and controlled by Waters Empower software (Waters, Milford, MA, the USA). A XP ODS-A C18 column (4.6 × $250 \mathrm{~mm}$ i.d., $5 \mu \mathrm{L}$, H\&E Co. Ltd., China) was employed with column temperature maintained at $30{ }^{\circ} \mathrm{C}$. All solvents and samples were filtered through a $0.22 \mu \mathrm{m}$ membrane prior to chromatography analysis. The mobile phases A and B were $0.17 \%$ aqueous acetic acid and acetonitrile, respectively. The gradient of solvent $\mathrm{B}$ was as follows: 0-4 min, $6 \%$; 4-16 $\mathrm{min}$, from $6 \%$ to $14 \%$; $16-18 \mathrm{~min}$, from $14 \%$ to $15 \%$; $18-32 \mathrm{~min}$, from $15 \%$ to $18 \%$; 32-34 $\mathrm{min}, 18 \%$; 34-37 $\mathrm{min}$, from $18 \%$ to $29 \%$; $37-45 \mathrm{~min}$, from $29 \%$ to $45 \%$; $45-50 \mathrm{~min}$, $45 \%$; 50-51 min, from $45 \%$ to $6 \%$; then kept at $6 \%$ for $10 \mathrm{~min}$. Solvent flow rate was $1.0 \mathrm{~mL} / \mathrm{min}$ and a $10 \mu \mathrm{L}$ injection of each sample was made onto the column. MCI-gel CHP20P (20-100 $\mu \mathrm{m}$, Mitsubishi Chemical Co. Ltd., Japan), Sephadex LH-20 (25-100 $\mu \mathrm{m}$, Pharmacia Fine Chemical Co. Ltd., Sweden), ODS-A C18 silica gel (50 $\mu \mathrm{m}$, YMC Co. Ltd., Japan), and polyamide (100-200 mesh, Luqiaosijia Biochemical Co. Ltd., Zhejiang, China) were used for CC. Polyamide CC was carried out with the eluant of $40 \%$ aqueous $\mathrm{MeOH}$. Aqueous $\mathrm{MeOH}$ from 0 to $100 \%(\mathrm{v} / \mathrm{v})$ in increments of 10\% was used as eluant for all Sephadex LH-20, and ODS-A CC. Silica gel (GF254, Liangchen Chemical Co. Ltd., Huoshan, China) thin layer chromatography experiments were performed with chloroform/methanol $/ \mathrm{H}_{2} \mathrm{O}(7: 3: 0.5, \mathrm{v} / \mathrm{v})$, or ethyl acetate/methanol $/ \mathrm{H}_{2} \mathrm{O}(100: 17: 13$, $\mathrm{v} / \mathrm{v}$ ), and spots were detected by UV illumination followed by spraying with $2 \%$ ethanolic $\mathrm{FeCl}_{3}$.

The standard sugar of L-rhamnose was purchased from Shanghai Hushi Laboratorial Equipment Co. Ltd., D-glucose and L-arabinose were purchased from Sigma, the USA. 5-FU, MTT, and DMSO 
for the cytotoxic activity assay were purchased from Sigma Chemical Co. Ltd. Media and serum were purchased from Gibco (Invitrogen Co. Ltd., the USA). Standard FGs of camellikaempferoside A (1), camelliquercetiside C (2), myricetin-3-rutinoside (3), quercetin-3- $O$-[ $\beta$-D-glucopyranosyl$(1 \rightarrow 3)$ - $O$ - $\alpha$-L-rhamnopyranosyl-( $(\rightarrow 6)-O$ - $\beta$-D-glucopyranoside] (4), vitexin-2" $-\alpha$-Lrhamnopyranoside (5), rutin (6), kaempferol-3- $O$-[ $\beta$-D-glucopyranosyl-( $1 \rightarrow 3)-O-\alpha-\mathrm{L}-$ rhamnopyranosyl- $(1 \rightarrow 6)-O-\beta$-D-glucopyranoside] (7) were isolated from FBT in our laboratory (Luo et al. 2013). The purity was not less than 95\% by HPLC analysis. Myricetin (8), quercetin (9), kaempferol (10) were purchased from Shanghai Ronghe Science Technology Development Co., Ltd. Trimethylsilylimidazole for sugar derivation was purchased from Adamas Reagent Co., Ltd., Switzerland.

\section{Materials}

FBT (produced in December, 2006) was purchased from Yiyang Fu Cha Industry Development Co. Ltd. (Yiyang, Hunan Province, PR China). The tea samples for HPLC analysis (BFFT and AFFT, respectively produced in March and April 2012 as the same production batch) were supplied by the same company. The samples of AFFT and BFFT were stored in $-20^{\circ} \mathrm{C}$ before being prepared for HPLC analysis.

\section{Extraction and Isolation}

The 70\% aqueous acetone extract of commercial FBT (3.6 kg) was separated successively by partitioning with petroleum ether, $\mathrm{CHCl}_{3}, n-\mathrm{BuOH}$ and Water. The $n-\mathrm{BuOH}$ solution was concentrated under reduced pressure to afford a brown residue (500 g) (Luo et al. 2013). This residue was applied to a Sephadex $\mathrm{LH}-20 \mathrm{CC}$ and eluted by $\mathrm{MeOH}-\mathrm{H}_{2} \mathrm{O}$ (from 0:1 to 1:0, 10\% stepwise gradient, each 1.5 L), yielding three fractions (S1-S3). The fraction S2 was further purified by $\mathrm{MCI}$-gel CC with $\mathrm{MeOH}-\mathrm{H}_{2} \mathrm{O}$ (from 0:1 to 1:0, 10\% stepwise gradient, each $0.5 \mathrm{~L}$ ) as the mobile phase, obtaining eleven fractions (S2-a to S2-k). The fraction S2-h was purified using polyamide $\mathrm{CC}$ with acetone- $\mathrm{H}_{2} \mathrm{O}(1: 2, \mathrm{v} / \mathrm{v})$, giving seven fractions ( $\mathrm{S} 2-\mathrm{h}-1$ to $\left.\mathrm{S} 2-\mathrm{h}-7\right)$. The fraction S2-h-5 was purified using ODS CC with $\mathrm{MeOH}-\mathrm{H}_{2} \mathrm{O}(5: 4, \mathrm{v} / \mathrm{v})$ to afford compounds 1 (39.5 mg) and 2 (14 mg).

\section{Spectroscopic Data}

Camellikaempferoside A: Kaempferol 3-O-[E-p-coumaroyl- $(\rightarrow 2)][\alpha$-L-arabinopyranosyl- 
$(1 \rightarrow 3)][\alpha$-L-rhamnopyranosyl $(1 \rightarrow 6)]-\beta$-D-glucopyranoside $(\mathbf{1})$, yellow amorphous powder; $[\alpha]_{D}^{25}-$ 88.9383 (c 0.0027, MeOH). IR (KBr) cm ${ }^{-1}: 3428,2923,2853,1655,1606,1514,1448,1362$, $1261,1208,1171,1081,834,581,519 . \mathrm{UV} \lambda_{\max }^{\mathrm{MeOH}} \mathrm{nm}(\log \varepsilon): 215$ (4.22), 268 (3.95), 315 (4.10). ESI-MS: $m / z 895[\mathrm{M}+\mathrm{Na}]^{+}, 1767[2 \mathrm{M}+\mathrm{Na}]^{+}$in positive mode. HRESI-MS: $m / z$ 895.2252 (calcd. for $\mathrm{C}_{41} \mathrm{H}_{44} \mathrm{O}_{21} \mathrm{Na}^{+}, 895.2267$ ) in positive mode. ${ }^{1} \mathrm{H}$ and ${ }^{13} \mathrm{C}$ NMR data, see Table $\mathrm{S} 1$.

\section{Determination of Sugar Components}

The determination of monosaccharides in $\mathbf{1}$ was established by a slightly modified method reported in the references (Li et al. 2014; Zong et al. 2015). Compound $1(0.8 \mathrm{mg}$ ) was dissolved in $2 \mathrm{M} \mathrm{HCl}$ $(0.8 \mathrm{~mL})$ and heated at $80^{\circ} \mathrm{C}$ for $4 \mathrm{~h}$. The reaction mixture was extracted with chloroform $(0.8 \mathrm{~mL} \times$ 2 ), and then the aqueous layer was freeze dried to give a mixture of monosaccharides. The residue was dissolved in a pyridine solution $(0.2 \mathrm{~mL})$ of L-cysteine methyl ester hydrochloride $(10 \mathrm{mg} / \mathrm{mL})$ and reacted at $60^{\circ} \mathrm{C}$ for $2 \mathrm{~h}$, the solvent was evaporated in vacuo, and $0.2 \mathrm{~mL}$ trimethylsilylimidazole was added. Then the mixture was heated at $70{ }^{\circ} \mathrm{C}$ for $1.5 \mathrm{~h}$. After partition between hexane $(0.5 \mathrm{~mL})$ and $\mathrm{H}_{2} \mathrm{O}$, the hexane extract was analysed by GC-MS. The standard sugars were prepared by the same method. The retention times of D-glucose, L-rhamnose and Larabinose were $21.67 \mathrm{~min}, 18.33 \mathrm{~min}$ and $16.76 \mathrm{~min}$, respectively (Figure S11).

\section{Cell Culture}

MCF-7 and MDA-MB-231 cells, were generously donated by Prof. Zhijie Chang (Tsinghua University School of Medicine, Beijing, PR China), and were kept in our lab and maintained in Dulbecco's Modified Eagle's Medium (DMEM) supplemented with 10\% fetal bovine serum (FBS). All the cells were kept at $37^{\circ} \mathrm{C}$ in a $5 \% \mathrm{CO}_{2}$ containing atmosphere. Media and serum were purchased from Gibco (Invitrogen Corporation, NY).

\section{MTT Assay}

Anti-proliferative activity assay of $\mathbf{1}$ was carried out by MTT colorimetric method with slight modification (Yang et al. 2010). MCF-7 and MDA-MB-231 cells were seeded on 96-well plates at a density of $1 \times 10^{3}$ cell/well overnight. Adherent cells were antiseptically treated with 5-FU or different concentrations of 1 for $72 \mathrm{~h}$. Then $20 \mu \mathrm{L} 5 \mathrm{mg} / \mathrm{ml}$ MTT was added into each well of the 96-well plates. After incubation for $4 \mathrm{~h}$, the cells culture medium was discarded and the purple precipitate attached in the bottom of the plates were dissolved in DMSO for $10 \mathrm{~min}$ in the dark. 
Bio-Rad model 680 microplate reader was used to obtain the absorbance at $570 \mathrm{~nm} / 630 \mathrm{~nm}$. 


\section{HPLC Analysis of Some FGs in FBT}

The FGs 2-7 were isolated from FBT in our experiments and were applied for quantitation (Luo et al. 2013). The content of $\mathbf{1}$ was not able to be calculated for its low concentration, though it could be detected in HPLC-PDA of BFFT and AFFT (Figure S15).

\section{Preparation of Standard Solutions for HPLC Analysis}

Compounds 1-10 were respectively weighed and dissolved in 70\% aqueous methanol by ultrasonic treatment [with the concentrations of 0.00875 (1), 0.029575 (2), 0.1 (3), 0.32 (4), 0.101 (5), 0.122 (6), 0.27 (7), 0.02 (8), 0.020625 (9), 0.016625 (10) $\mathrm{mg} / \mathrm{mL}$, respectively]. The linear calibration curves contained six different concentrations of each standard compound diluted with $70 \%$ aqueous methanol. All samples were stored in $-20{ }^{\circ} \mathrm{C}$ until analysis.

\section{Preparation of Tea Extracts for HPLC Analysis}

The whole bricks of BFFT and AFFT were milled into powder and dehydrated, respectively. Each of tea samples $(2.500 \mathrm{~g})$ was saturated in $70 \%$ aqueous methanol $(100 \mathrm{~mL})$ for $12 \mathrm{~h}$ at room temperature, during which an ultrasonic bath was carried out twice for $15 \mathrm{~min}$. A $2 \mathrm{~mL}$ aliquot of the liquid extract was centrifuged at 10,000 rpm for $10 \mathrm{~min}$ and then the supernatant was passed through a $0.22 \mu \mathrm{m}$ filter disk for HPLC analysis. The experiments were performed in triplicate, and the results of quantitation analysis were expressed as mean values with standard deviations.

\section{Statistical Analysis}

The data in Figure S16 were presented as means \pm SD. The values were evaluated by the Student's $t$-test using Excel 2007 Software (Microsoft Software Inc.). Differences were considered as $*(\mathrm{p}<0.05)$ and $* *(\mathrm{p}<0.01)$.

\section{Identification of 2-10 in BFFT and AFFT}

The peaks were identified by the retention times of authentic samples, which were 43.096 (1), 42.335 (2), 27.210 (3), 30.763 (4), 32.074 (5), 33.497 (6), 36.812 (7), 41.723 (8), 45.013 (9), and 47.926 (10) min, respectively. In addition, the peaks of $\mathbf{1}$ in chromatography of BFFT and 
AFFT were confirmed by HPLC-PDA method, in which the UV spectra (200-400 nm) were compared with that of $\mathbf{1}$ (Figure S14). Compound $\mathbf{1}$ was not indicated as a product of fungal fermentation as it was detected in both BFFT and AFFT.

\section{Quantitation of 2-10 in BFFT and AFFT}

The concentration of $\mathbf{1}$ was too low to be quantitated by the current method. The contents of $\mathbf{2}-$ 10 were calculated and compared between BFFT and AFFT. The contents of quercetin and its $O$-glycosides $(4,6$ and 9$)$ were decreased significantly after fungal fermentation procedure. While the contents of vitexin-2"- $\alpha$-L-rhamnopyranoside (5) and camelliquercetiside C (2) were increased (Figure S16, Table S5).

\section{Method Validation for the Quantitation of Some FGs (2-10) in FBT}

\subsection{Linearity}

A series of solutions of 2-10 were prepared to establish the linearity of the proposed method. Calibration curves showed good linearity over the concentration range in all samples with correlation coefficients (R) larger than 0.999 (Table S2).

\subsection{Precision, Repeatability and Stability}

The precision were assessed by determining standard samples of stock solution at medium concentration levels continuously on the same day $(n=5)$. The repeatability were determined by assaying parallel FBT samples repeatedly on the same day $(n=5)$. The stability was determined by tea samples on $0,4,8,12$ and $24 \mathrm{~h}$. Relative standard deviations (RSDs) of the precision, repeatability and stability were all less than 7\% (Table S3).

\subsection{Limit of Detection and the Lower Limit of Quantification}

The limits of detection (LOD, $\mathrm{S} / \mathrm{N}=3$ ) for 2-10 were $0.45,0.38,0.42,0.45,0.71,0.54,0.2,0.43$, and $0.61 \mu \mathrm{g} / \mathrm{mL}$, respectively. The lower limits of quantification (LOQ, $\mathrm{S} / \mathrm{N}=10$ ) for 2-10 were $1.44,1.08,1.24,1.36,2.31,1.56,0.53,1.26$, and $1.95 \mu \mathrm{g} / \mathrm{mL}$, respectively. 


\subsection{Recoveries}

A certain amount of reference substances (low, medium, and high concentrations) were added into a certain amount of BFFT or AFFT samples (precisely weighted $0.25 \mathrm{~g}$ ), respectively, and were then extracted and analysed under the proposed method. Three replicate extractives at each level were used to determine the extraction recovery rates and the RSDs were calculated. The recoveries of the investigated FGs were between 90-110\% with RSD values less than $5.0 \%$ (Table S4).

In addition to camellikaempferoside $A$, the present work discovered that the contents of 4, 6 and 9 were decreased by fungal fermentation, though no significant change was observed on variety of FGs between BFFT and AFFT (Figure S12). Therefore, the metabolic mechanism of the microorganisms on these FGs may be interesting research areas in future (Figure S12), which will help to understand the generation mechanism of the special flavor and functions of Fuzhuan brick-tea.

\section{References}

Li X, Zhao JP, Peng CP, Chen Z, Liu YL, Xu QM, Khan IA, Yang SL. 2014. Cytotoxic triterpenoid glycosides from the root of Camellia oleifera. Planta Med. 80:590-598.

Yang SG, Zhang X, Sun XS, Ling TJ, Feng Y, Du XY, Zhao M, Yang Y, Xue D, Wang L, Liu RT. 2010. Diverse ecdysterones show different effects on amyloid- $\beta_{42}$ aggregation but all uniformly inhibit amyloid- $\beta_{42}$-induced cytotoxicity. Int. J. Alzheimers. Dis. 22:107117.

Zong JF, Wang RL, Bao GH, Ling TJ, Zhang L, Zhang XF, Hou RY. 2015. Novel triterpenoid saponins from residual seed cake of Camellia oleifera Abel. show anti-proliferative activity against tumor cells. Fitoterapia. 104:7-13. 


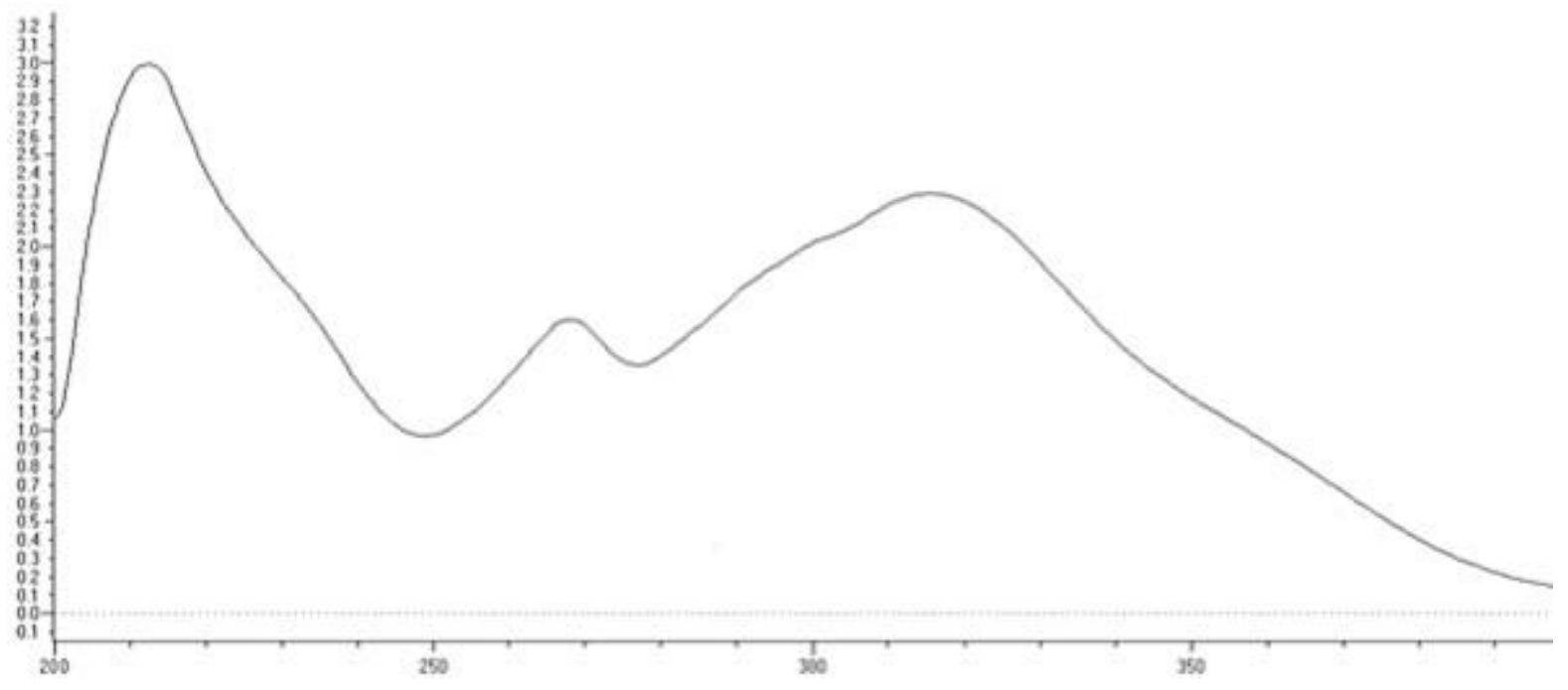

Figure S1: UV spectrum of 1 


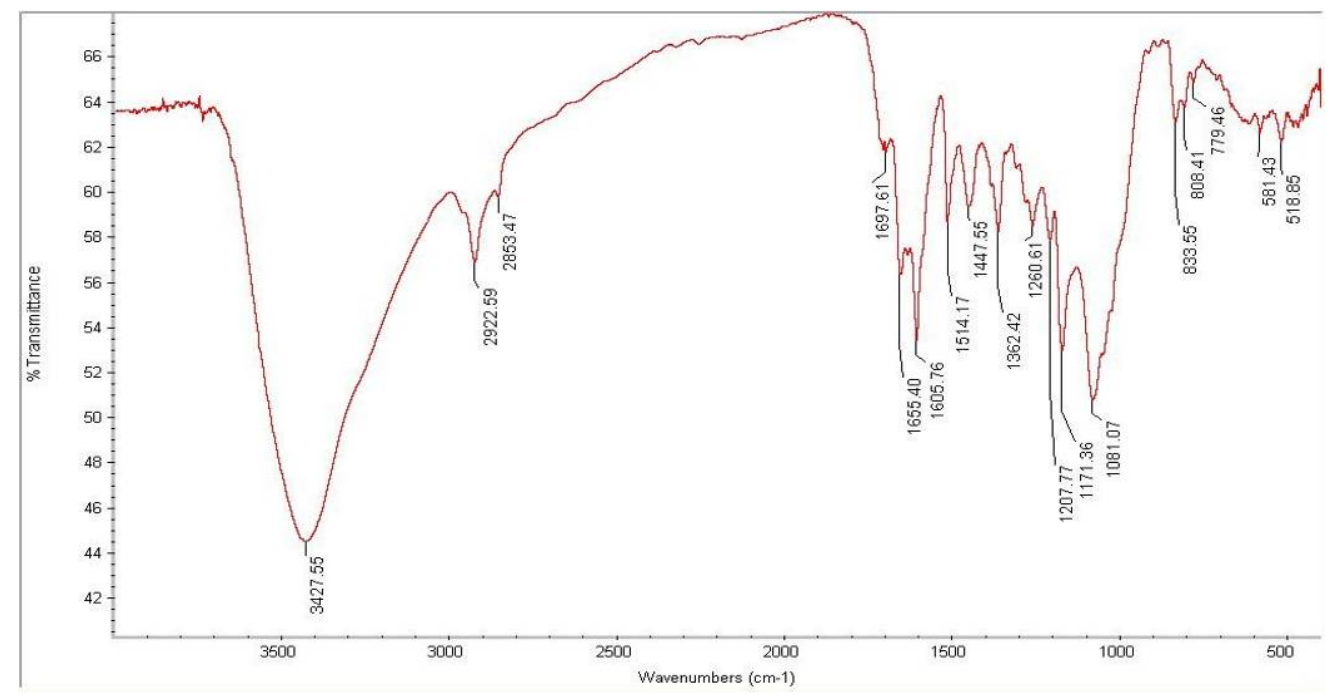

Figure S2: IR spectrum of 1

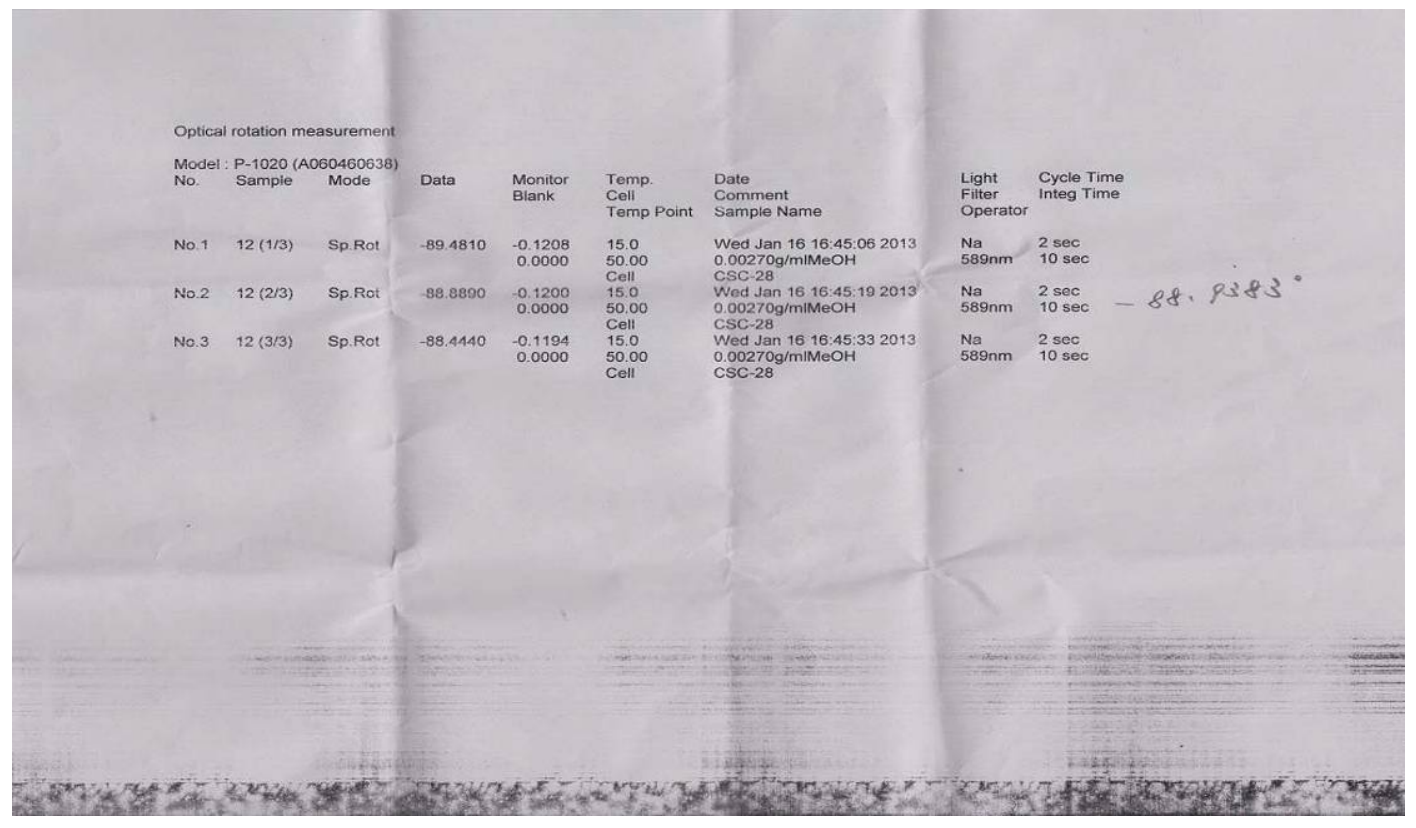

Figure S3: Optical rotation of $\mathbf{1}$ 


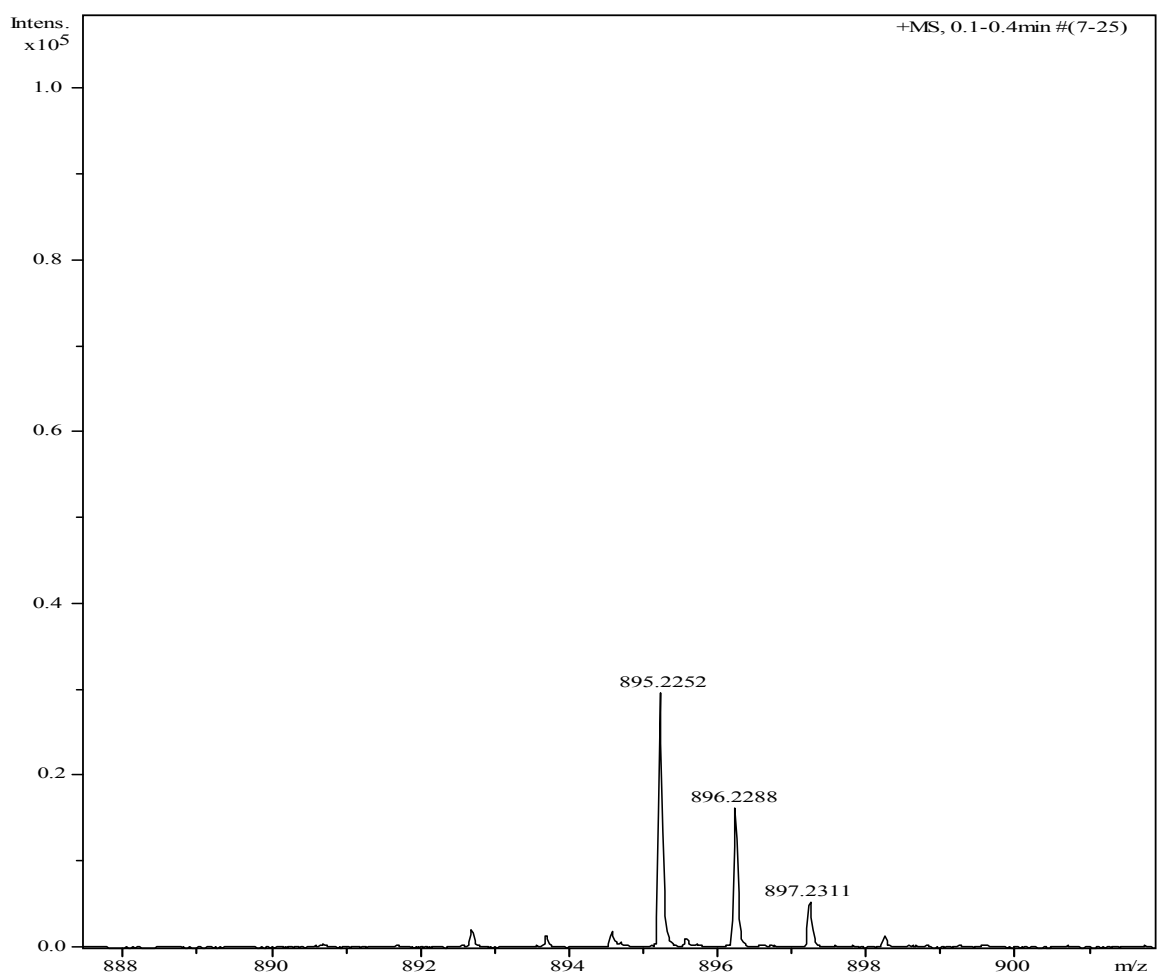

Figure S4: HRESI-MS spectrum of 1

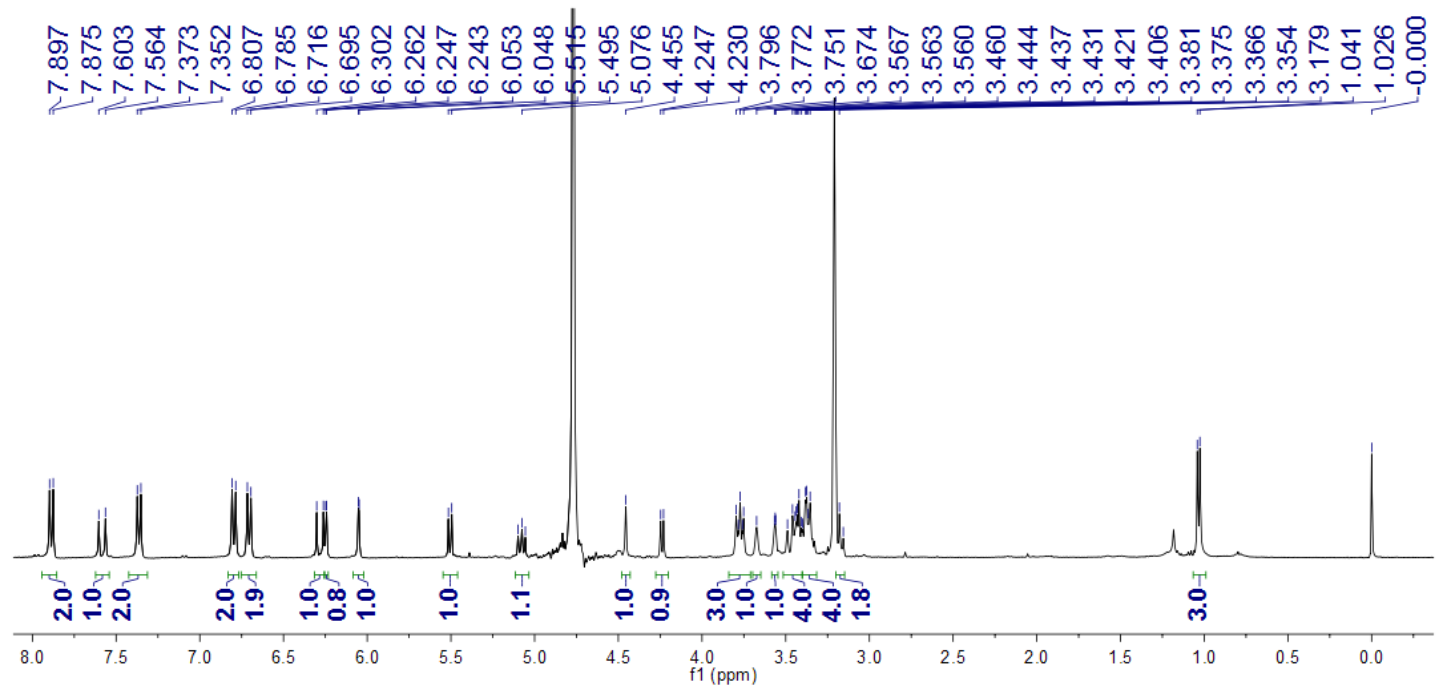

Figure S5: ${ }^{1} \mathrm{H}-\mathrm{NMR}$ of $\mathbf{1}$ (in Methanol- $d_{4}$ ) 


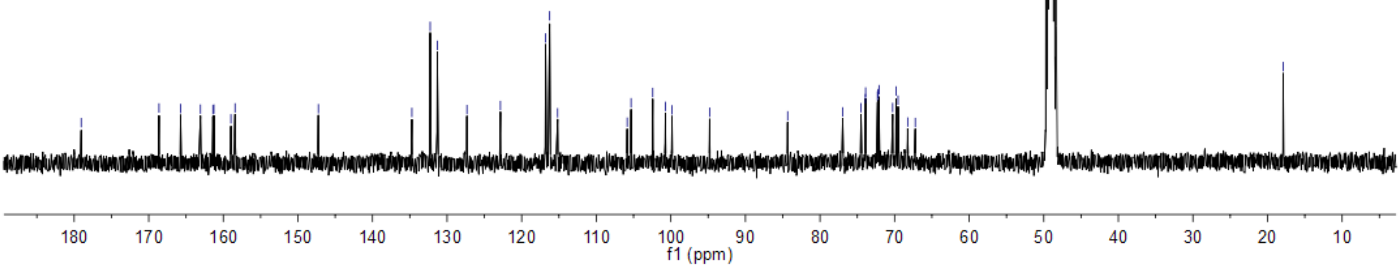

Figure S6: ${ }^{13} \mathrm{C}-\mathrm{NMR}$ of $\mathbf{1}$ (in Methanol- $d_{4}$ )

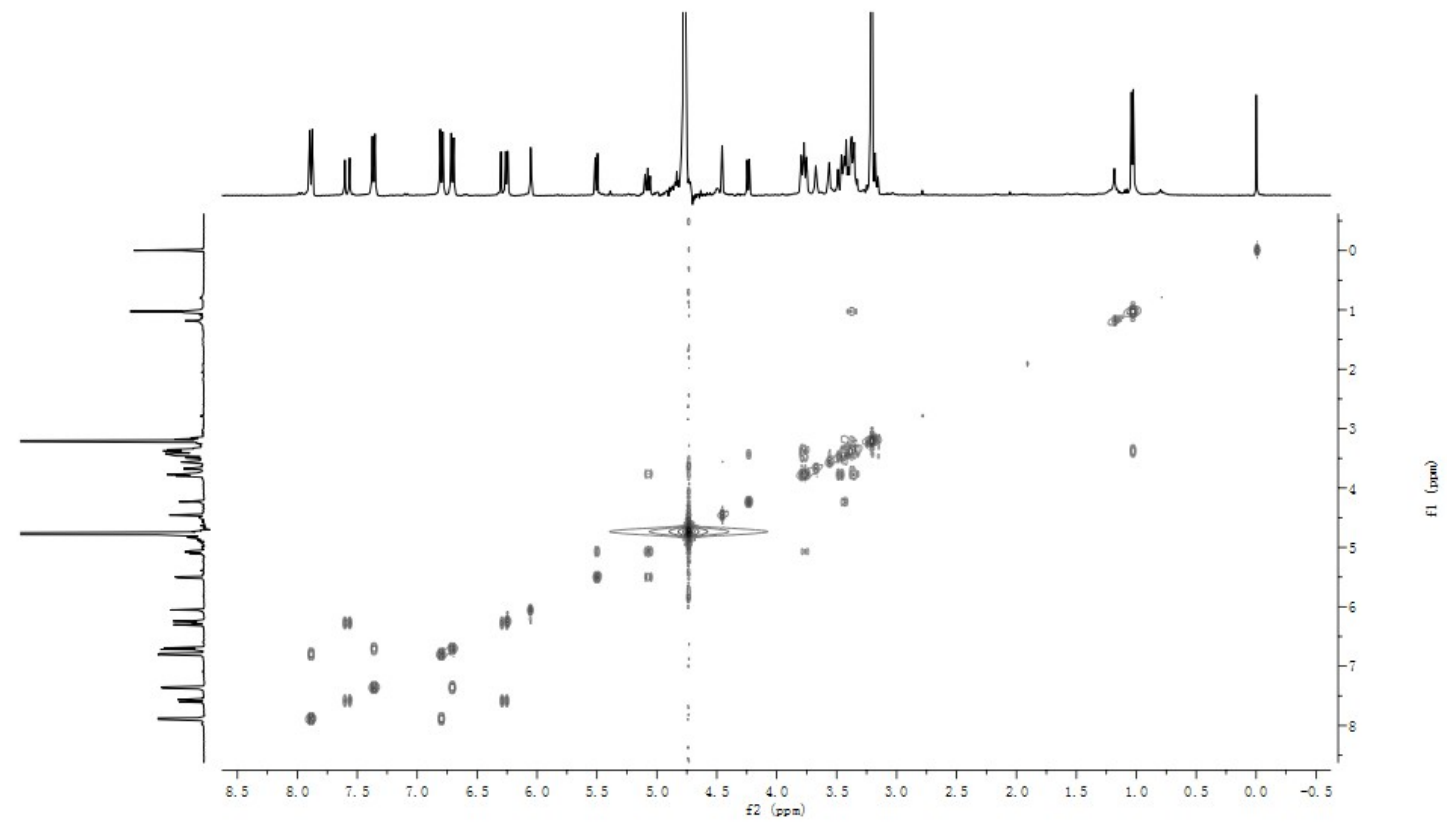

Figure S7: ${ }^{1} \mathrm{H}-{ }^{1} \mathrm{H}$ COSY of 1 (in Methanol- $d_{4}$ ) 


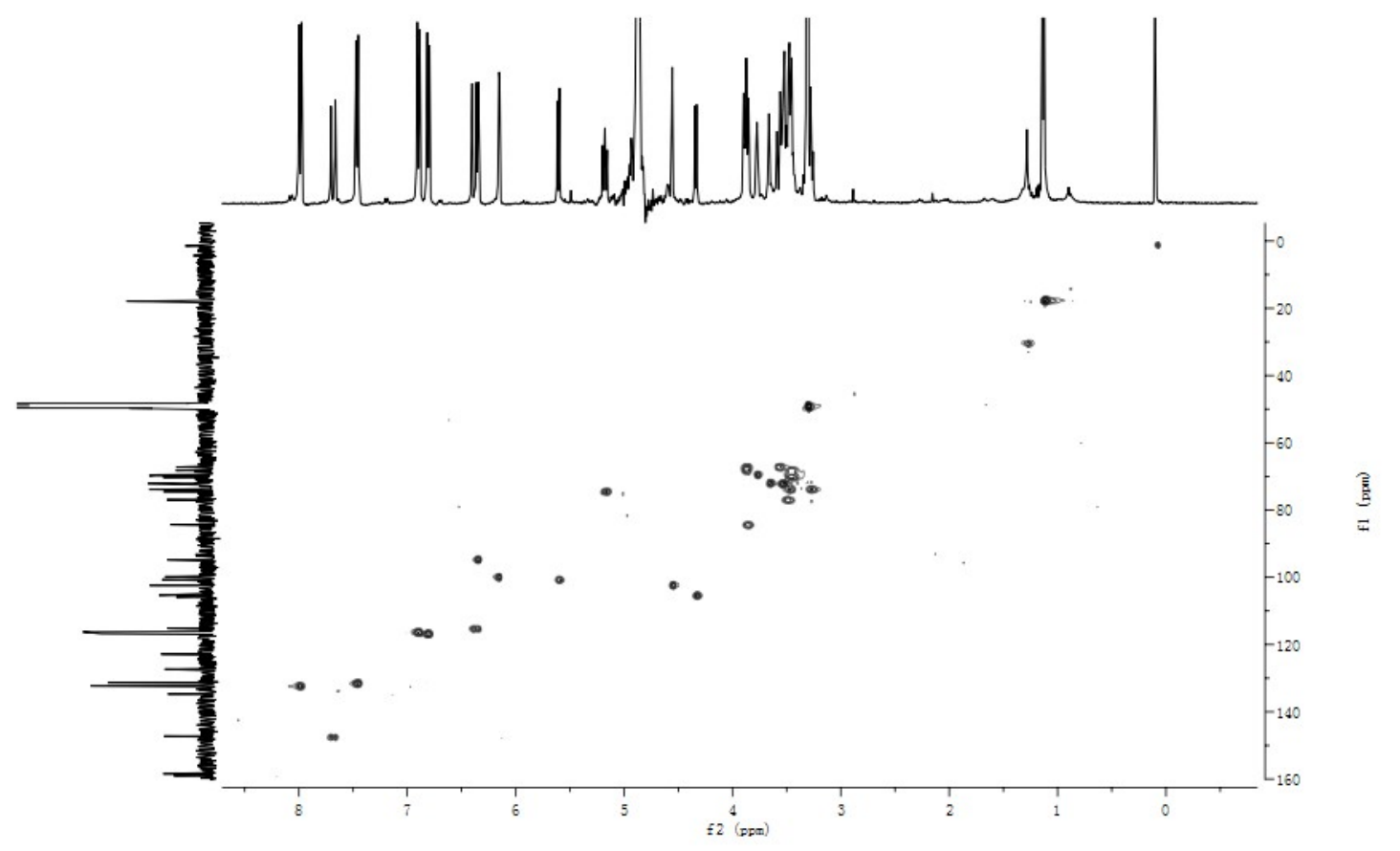

Figure S8: HSQC of 1 (in Methanol- $d_{4}$ ) 

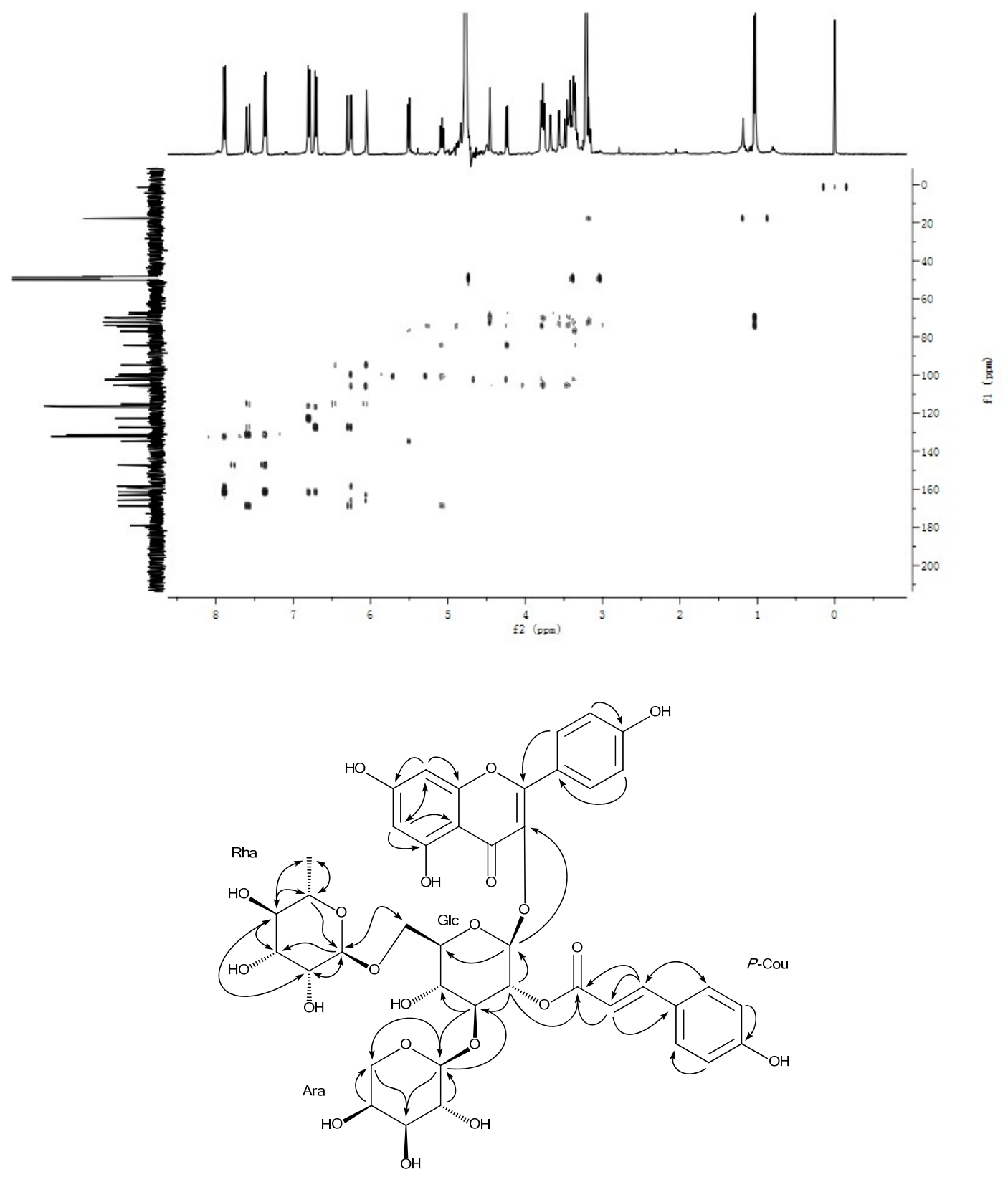

Figure S9: HMBC of 1 (in Methanol- $d_{4}$ ) 


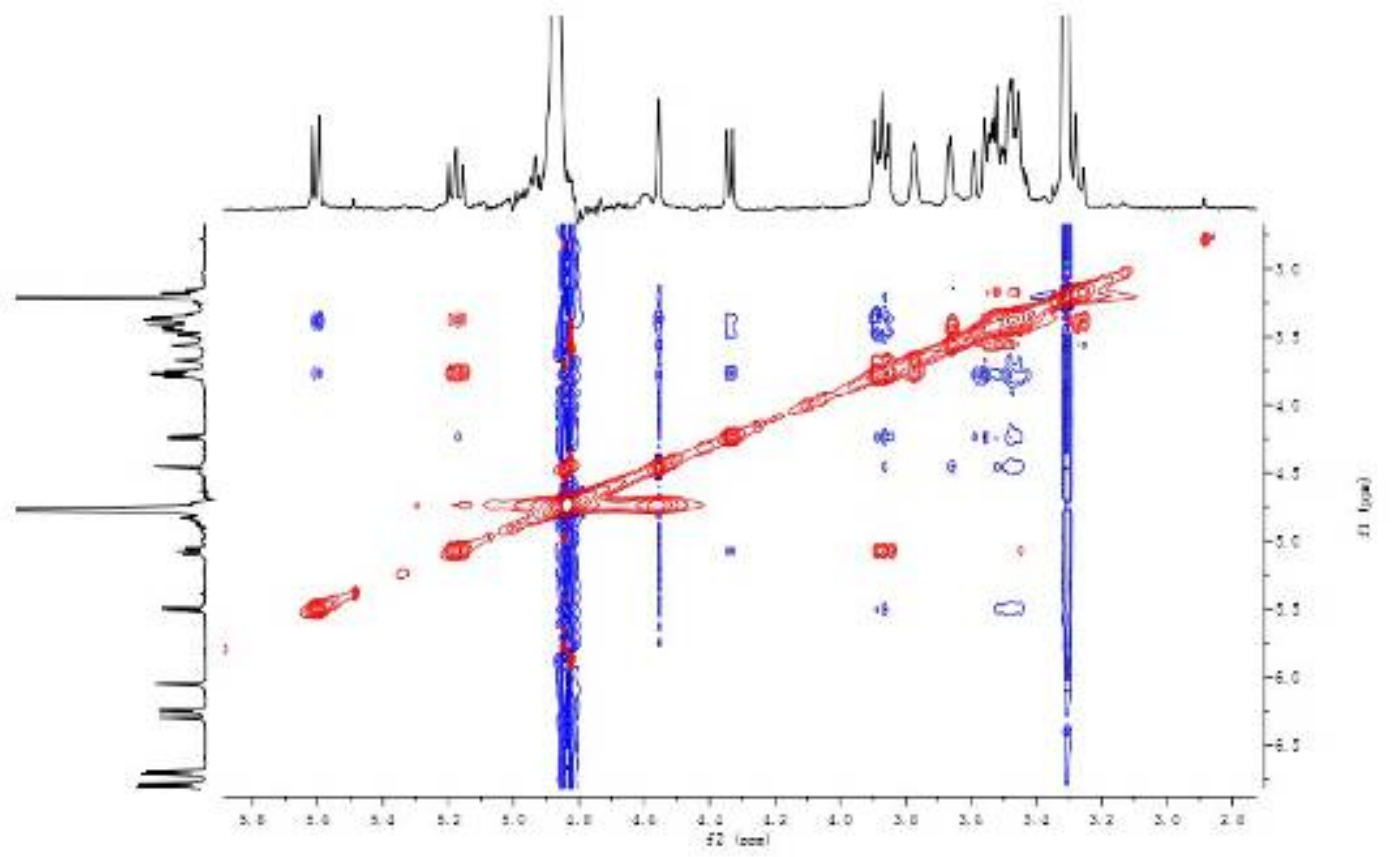

Figure S10: NOESY of 1 (in Methanol- $d_{4}$ ) 


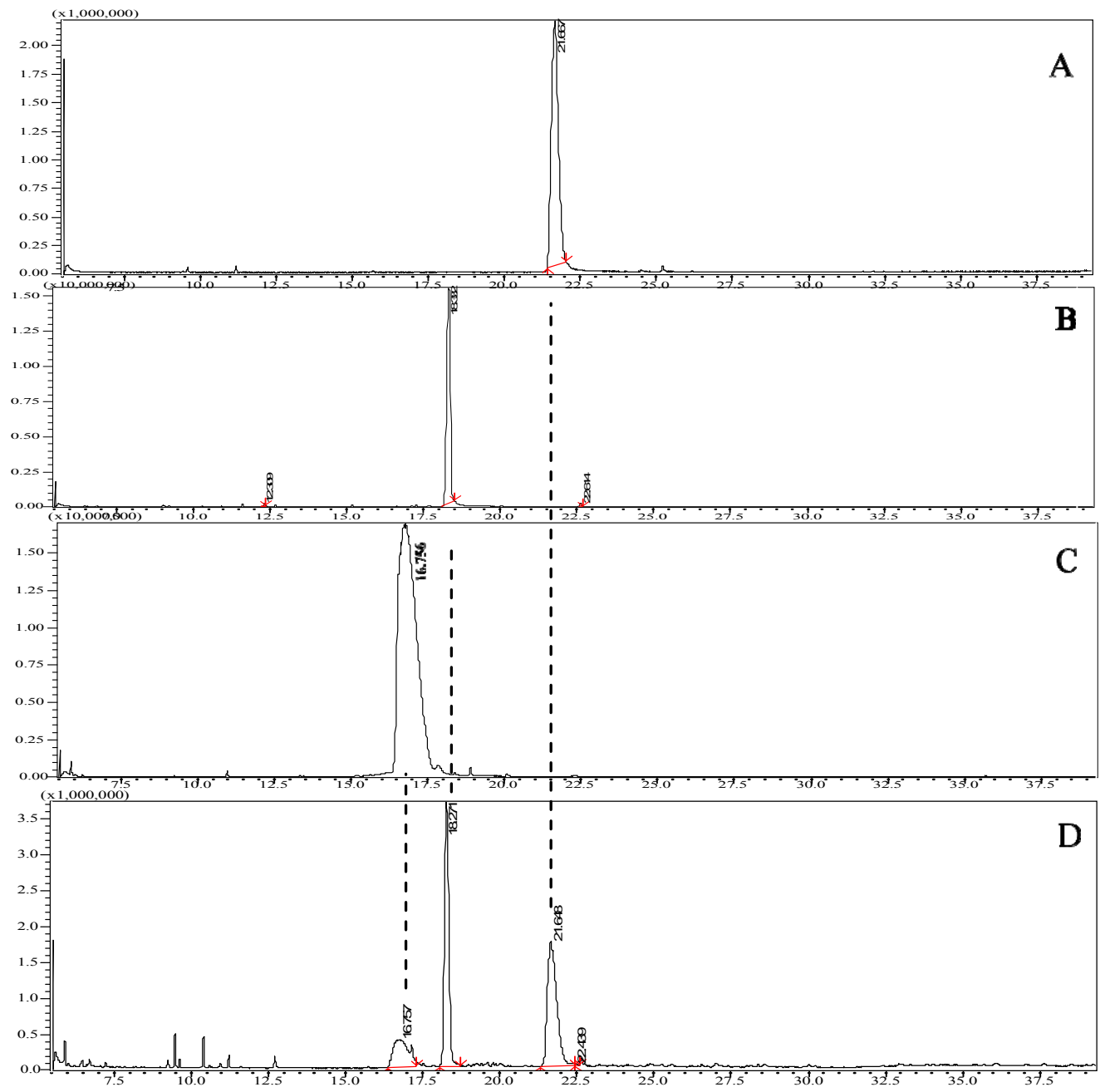

Figure S11: GC spectral comparison of the sugar units

Figure S11A: The retention time of $D$-glucose (21.67 min)

Figure S11B: The retention time of $L$-rhamnose (18.33 min)

Figure S11C: The retention time of $L$-arabinose (16.76 min)

Figure S11D: The retention times of the sugar units of 1 

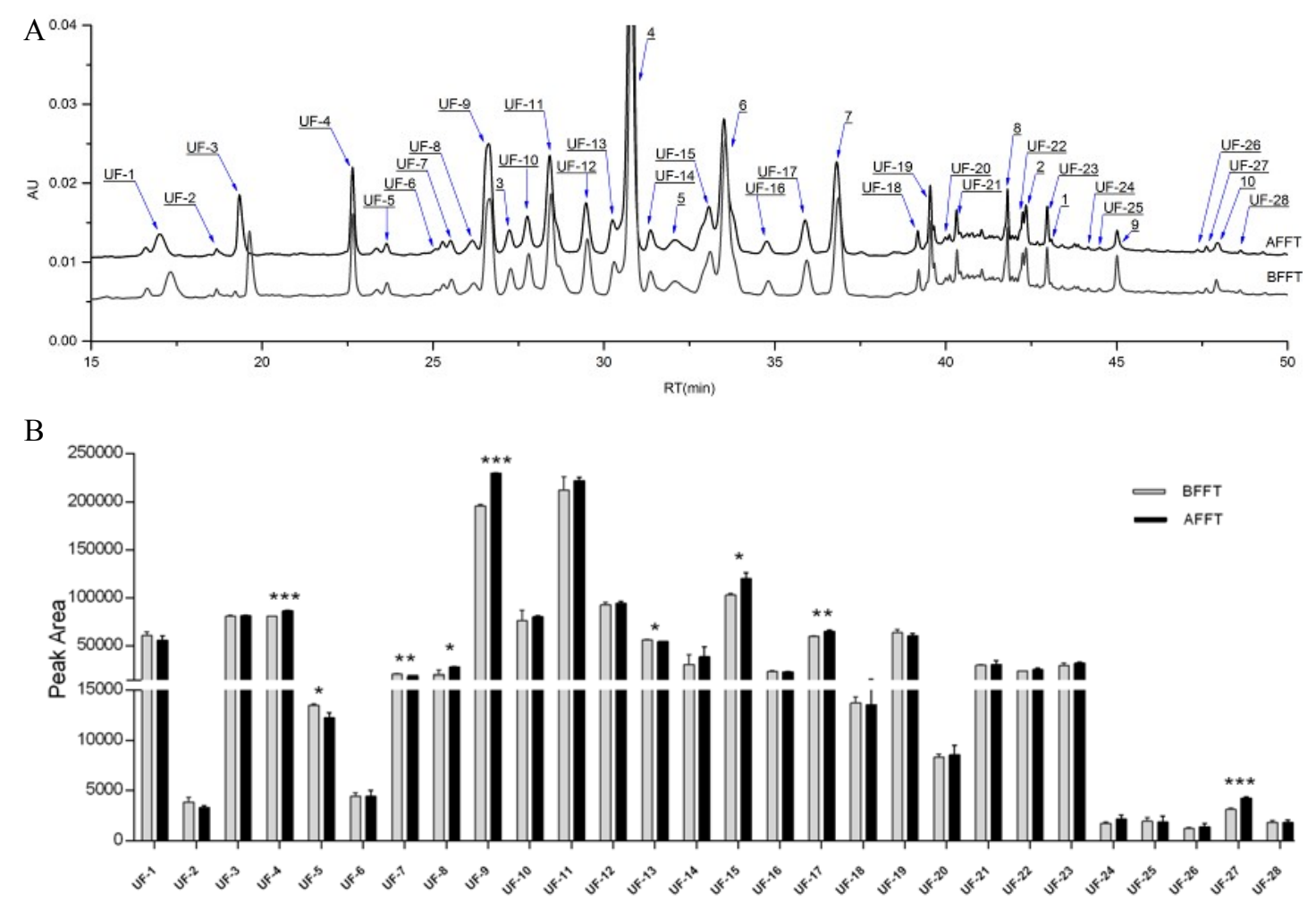

Figure S12: HPLC (350 nm) analysis for UF-1 to UF-28 in BFFT and AFFT

[A: HPLC (350 nm) of UF-1 to UF-28; B: the chromatographic area comparison of each UFs between BFFT and AFFT]

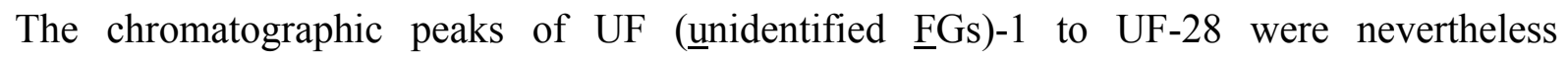
characterized as FGs preliminary by their UV spectra (see Figure S-13), though the exact structures of them were unknown yet.

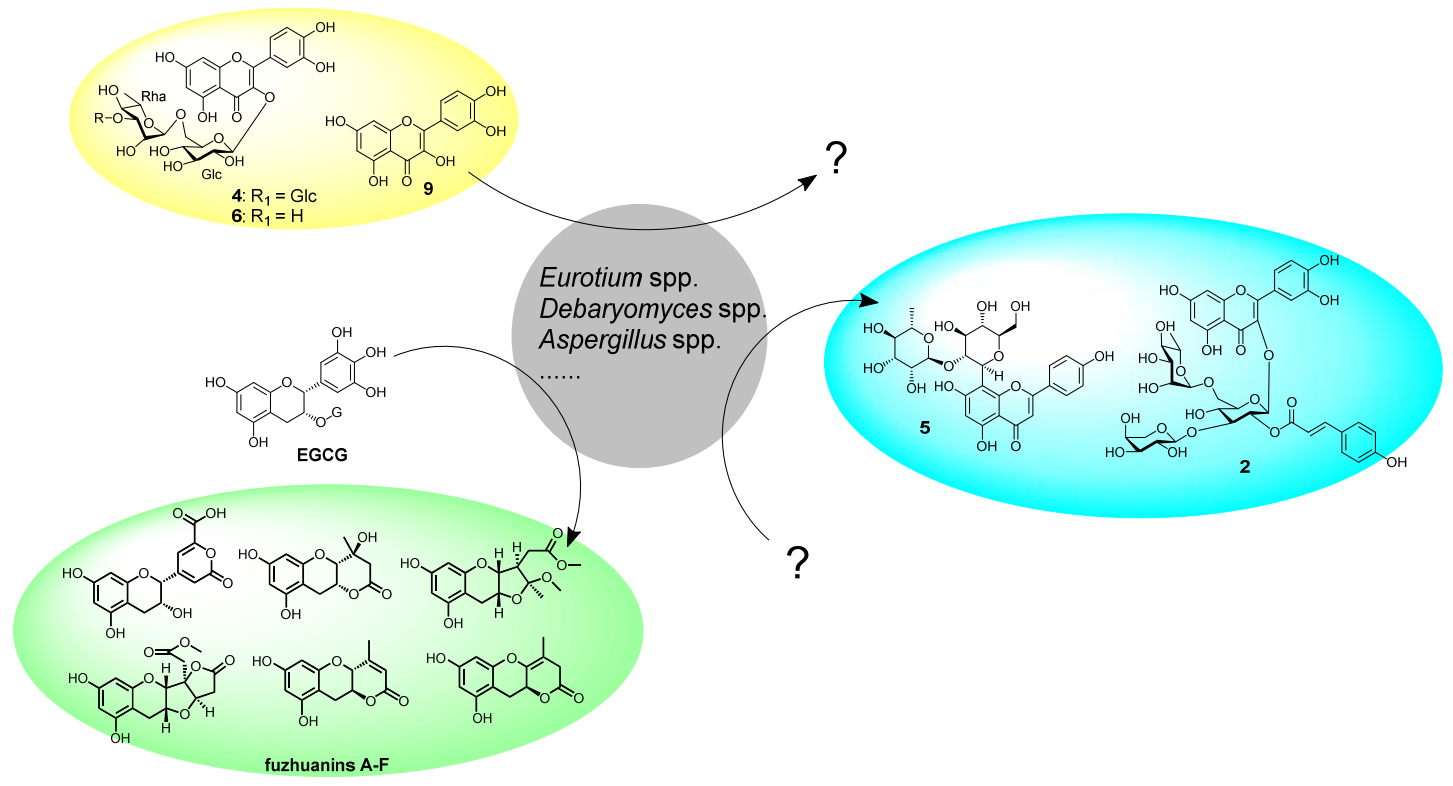

The mystery of fungal metabolism on FGs in FBT 

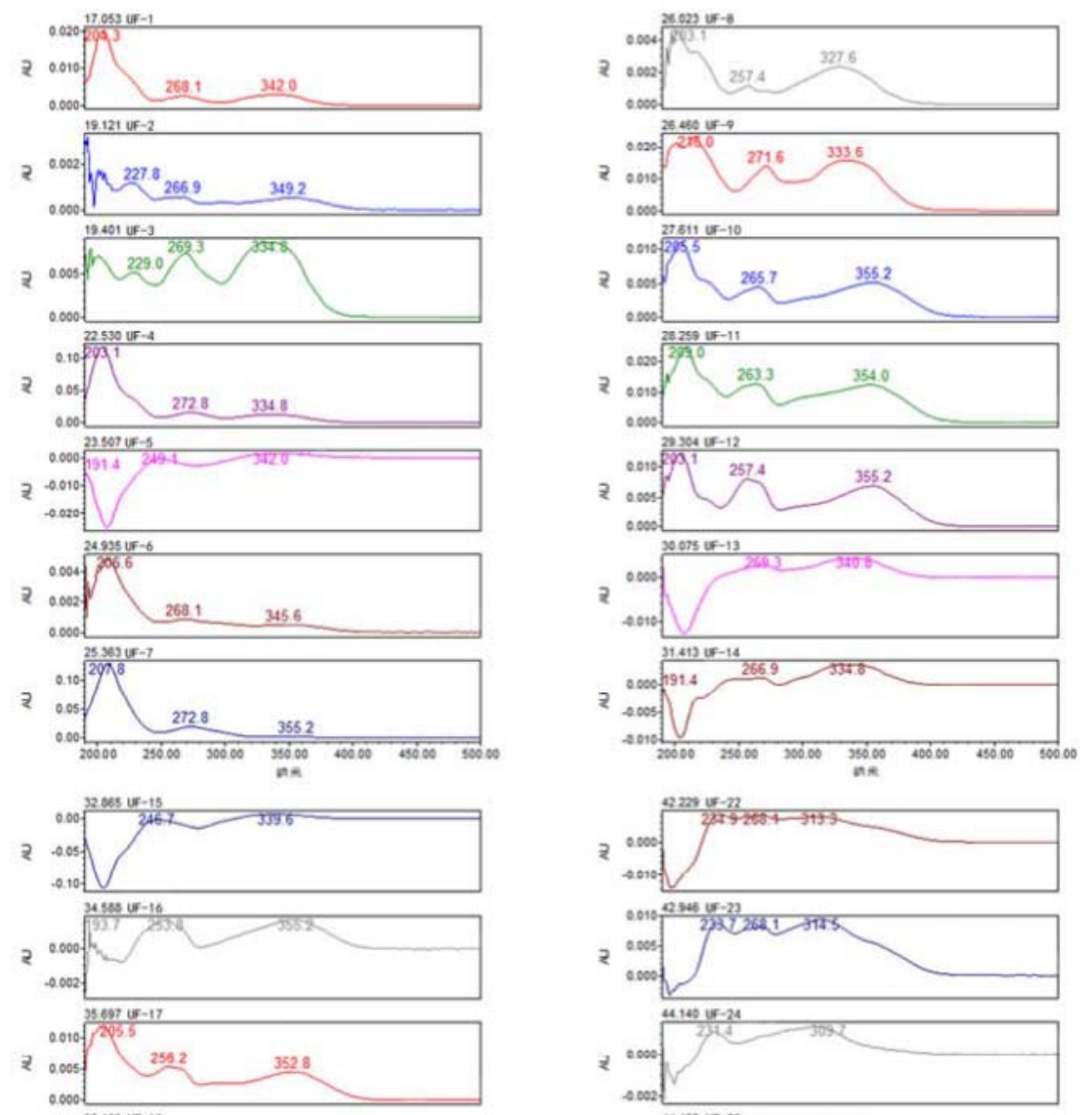

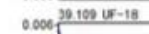

$z \underset{0.002}{0.004} \mathrm{n} 230022653 \quad 3145$
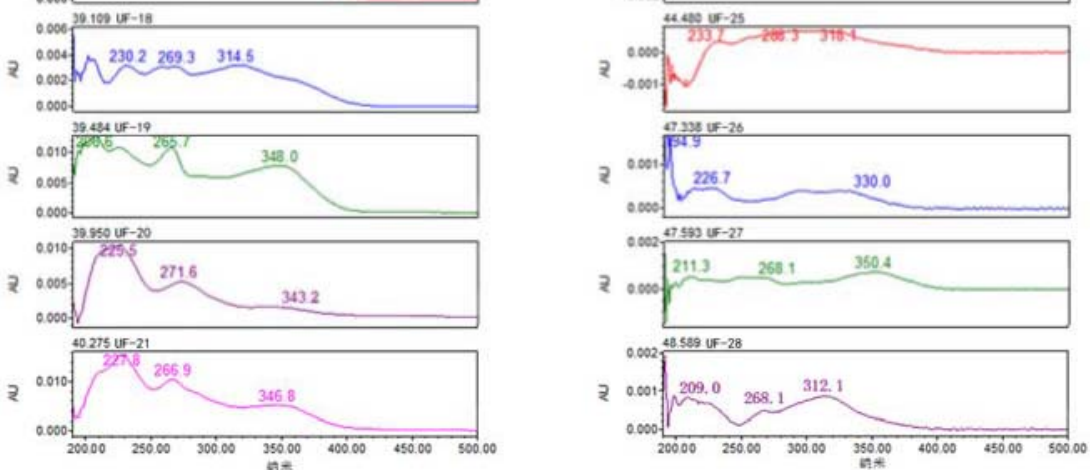

Figure S13: UV spectra of UF-1 to UF-28 in HPLC 


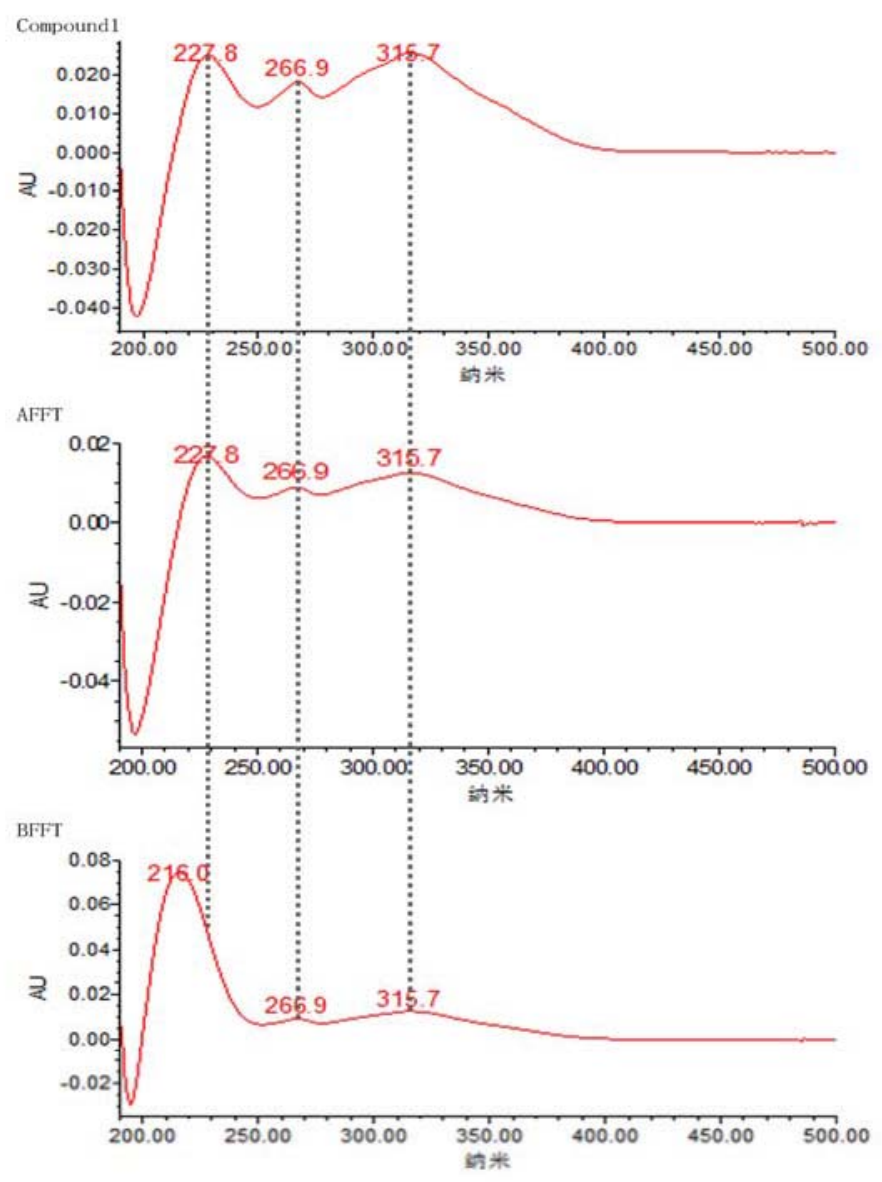

Figure S14: UV spectra of the chromatography peaks ( $\left.t_{\mathrm{R}} 43.096\right)$ in HPLC of $\mathbf{1}$, AFFT and BFFT

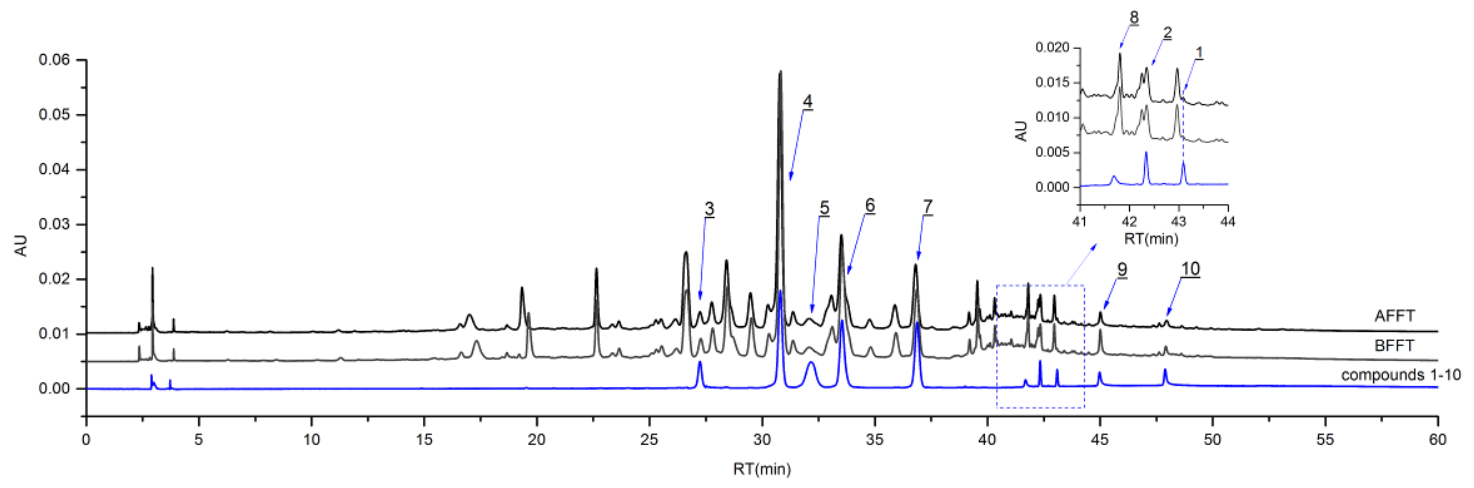

Figure S15: HPLC (350 nm) of the BFFT, AFFT and standard compounds 1-10 


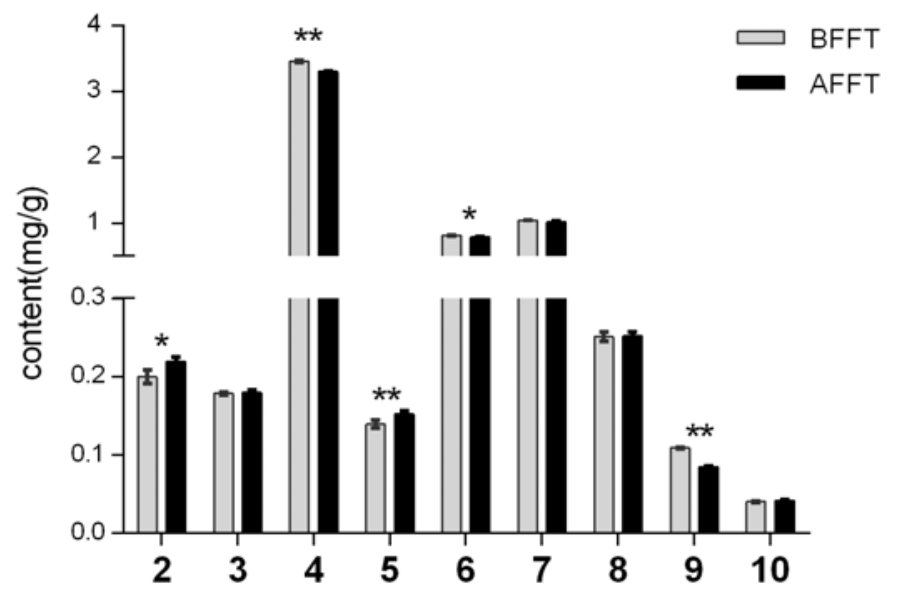

Figure S16: Quantitation analysis of 2-10 in BFFT and AFFT 
Table S1: NMR data of $\mathbf{1}$ and partial ${ }^{13} \mathrm{C}$ NMR data of $\mathbf{2}$

\begin{tabular}{|c|c|c|c|c|}
\hline \multirow{2}{*}{ Positions } & \multicolumn{3}{|c|}{$\mathbf{1}^{a}$} & \multirow{2}{*}{$\frac{2^{b}}{\delta_{\mathrm{C}}}$} \\
\hline & $\delta_{\mathrm{H}}(J$ in $\mathrm{Hz})$ & $\delta_{\mathrm{C}}$ & $\mathrm{HMBC}\left({ }^{1} \mathrm{H}\right.$ to $\left.{ }^{13} \mathrm{C}\right)$ & \\
\hline 2 & - & 158.98 & & 158.7 \\
\hline 3 & - & 134.72 & & 134.8 \\
\hline 4 & - & 179.05 & & 178.8 \\
\hline 5 & - & 163.06 & & 162.9 \\
\hline 6 & $6.050 \mathrm{~d}(2.0)$ & 99.84 & C- $5,7,8,10$ & 99.8 \\
\hline 7 & - & 165.73 & & 165.6 \\
\hline 8 & $6.245 \mathrm{~d}(2.0)$ & 94.80 & C- $6,7,9,10$ & 94.8 \\
\hline 9 & - & 158.43 & & 158.2 \\
\hline 10 & - & 105.85 & & 105.8 \\
\hline $1^{\prime}$ & - & 122.85 & & \\
\hline $2^{\prime}, 6^{\prime}$ & $7.887 \mathrm{~d}(8.8)$ & 132.26 & $\mathrm{C}-2,4^{\prime}$ & \\
\hline $3^{\prime}, 5^{\prime}$ & $6.796 \mathrm{~d}(8.8)$ & 116.25 & $\mathrm{C}-1^{\prime}, 4^{\prime}$ & \\
\hline $4^{\prime}$ & - & 161.39 & & \\
\hline \multicolumn{5}{|l|}{ Glc } \\
\hline 1 & $5.505 \mathrm{~d}(8.0)$ & 100.73 & C-3, Glc-6 & 100.8 \\
\hline 2 & $5.077 \mathrm{dd}(9.2,8.4)$ & 74.50 & C-Glc-(1, 3), Cou-1 & 74.6 \\
\hline 3 & $3.762 \mathrm{c}$ & 84.34 & C-Glc-4, Ara-1 & 84.5 \\
\hline 4 & $3.364 \mathrm{e}$ & 70.26 & C-Glc- $(3,5)$ & 70.3 \\
\hline 5 & $3.406 \mathrm{~m}$ & 76.96 & & 77.0 \\
\hline $6 a$ & $3.772 \mathrm{c}$ & 68.25 & C-Glc-5, Rha-1 & 68.3 \\
\hline $6 \mathrm{~b}$ & $3.356 \mathrm{e}$ & & C-Glc-5, Rha-1 & \\
\hline \multicolumn{5}{|l|}{ Ara } \\
\hline 1 & $4.238 \mathrm{~d}(6.8)$ & 105.33 & C-Glc-3, Ara- $(3,5)$ & 105.3 \\
\hline 2 & $3.431 \mathrm{~d}$ & 72.22 & C-Ara-1 & 72.3 \\
\hline 3 & $3.380 \mathrm{e}$ & 73.91 & & 74.0 \\
\hline 4 & $3.674 \mathrm{~m}$ & 69.54 & & 69.9 \\
\hline $5^{\mathrm{a}}$ & $3.772 \mathrm{c}$ & 67.23 & C-Ara-1 & 67.3 \\
\hline $5 b$ & $3.465 \mathrm{~m}$ & & C-Ara-1 & \\
\hline \multicolumn{5}{|l|}{ Rha } \\
\hline 1 & $4.455 \mathrm{~d}(1.6)$ & 102.42 & C-Glc-6, Rha- $(2,3,6)$ & 102.4 \\
\hline 2 & $3.565 \mathrm{dd}(3.2,1.6)$ & 72.09 & C-Rha- $(1,3,4)$ & 72.2 \\
\hline 3 & $3.431 \mathrm{~d}$ & 72.29 & C-Rha-4 & 72.3 \\
\hline 4 & $3.179 \mathrm{t}(9.2)$ & 73.89 & C-Rha- $(2,3,5,6)$ & 74.0 \\
\hline 5 & $3.364 \mathrm{e}$ & 69.80 & C-Rha- $(1,6)$ & 69.9 \\
\hline 6 & $1.033 \mathrm{~d}(6.0)$ & 17.91 & C-Rha- $(4,5)$ & 18.1 \\
\hline \multicolumn{5}{|l|}{$p$-Cou } \\
\hline $\mathrm{C}=\mathrm{O}$ & - & 168.62 & & 168.6 \\
\hline$\alpha$ & $6.282 \mathrm{~d}(16.0)$ & 115.18 & C-p-Cou- $\left(1,1^{\prime}\right)$ & 115.1 \\
\hline$\beta$ & $7.584 \mathrm{~d}(16.0)$ & 147.26 & C-p-Cou- $\left(1,2,2^{\prime}, 6^{\prime}\right)$ & 147.2 \\
\hline 1 & - & 127.34 & & 127.3 \\
\hline 2,6 & $7.362 \mathrm{~d}(8.4)$ & 131.31 & C-p-Cou- $\left(3,4^{\prime}\right)$ & 131.3 \\
\hline 3,5 & $6.705 \mathrm{~d}(8.4)$ & 116.79 & C-p-Cou- $\left(1,2^{\prime}, 4^{\prime}, 6^{\prime}\right)$ & 116.1 \\
\hline 4 & - & 161.27 & & 161.1 \\
\hline
\end{tabular}

Glc: glucopyranosyl, Ara: arabinopyranosyl, Rha: rhamnopyranosyl, $p$-Cou: $E$ - $p$-hydroxycoumaroyl 
Table S2: Linear calibration information for 2-10

\begin{tabular}{ccc}
\hline compounds & calibration curves & $\mathrm{R}$ \\
\hline $\mathbf{2}$ & $\mathrm{Y}=1.88 \mathrm{e}+007 \mathrm{X}-2.11 \mathrm{e}+004$ & 0.999209 \\
$\mathbf{3}$ & $\mathrm{Y}=1.38 \mathrm{e}+007 \mathrm{X}-1.42 \mathrm{e}+004$ & 0.999486 \\
$\mathbf{4}$ & $\mathrm{Y}=8.41 \mathrm{e}+006 \mathrm{X}-2.03 \mathrm{e}+004$ & 0.999612 \\
$\mathbf{5}$ & $\mathrm{Y}=1.55 \mathrm{e}+007 \mathrm{X}-1.30 \mathrm{e}+004$ & 0.999683 \\
$\mathbf{6}$ & $\mathrm{Y}=1.77 \mathrm{e}+007 \mathrm{X}-1.59 \mathrm{e}+004$ & 0.999651 \\
$\mathbf{7}$ & $\mathrm{Y}=6.95 \mathrm{e}+006 \mathrm{X}-9.31 \mathrm{e}+003$ & 0.999765 \\
$\mathbf{8}$ & $\mathrm{Y}=1.23 \mathrm{e}+007 \mathrm{X}-1.64 \mathrm{e}+004$ & 0.999384 \\
$\mathbf{9}$ & $\mathrm{Y}=7.31 \mathrm{e}+006 \mathrm{X}-1.02 \mathrm{e}+003$ & 0.999455 \\
$\mathbf{1 0}$ & $\mathrm{Y}=2.48 \mathrm{e}+007 \mathrm{X}-1.44 \mathrm{e}+004$ & 0.999226 \\
\hline
\end{tabular}


Table S3: Precision, repeatability and stability of 2-10

\begin{tabular}{cccc}
\hline compounds & $\begin{array}{c}\text { Precision } \\
(\mathrm{RSD} / \%)\end{array}$ & $\begin{array}{c}\text { Repeatability } \\
(\mathrm{RSD} / \%)\end{array}$ & $\begin{array}{c}\text { Stability } \\
(\mathrm{RSD} / \%)\end{array}$ \\
\hline $\mathbf{2}$ & 2.6 & 2.7 & 5.6 \\
$\mathbf{3}$ & 0.8 & 2.6 & 3.3 \\
$\mathbf{4}$ & 1 & 1.5 & 1.4 \\
$\mathbf{5}$ & 0.9 & 2.1 & 3.6 \\
$\mathbf{6}$ & 0.4 & 1.6 & 1.9 \\
$\mathbf{7}$ & 0.1 & 3.6 & 1.6 \\
$\mathbf{8}$ & 3.6 & 3.3 & 6 \\
$\mathbf{9}$ & 1.1 & 3 & 6.2 \\
$\mathbf{1 0}$ & 1.1 & 5.5 & 4.5 \\
\hline
\end{tabular}


Table S4: Recoveries of 2-10

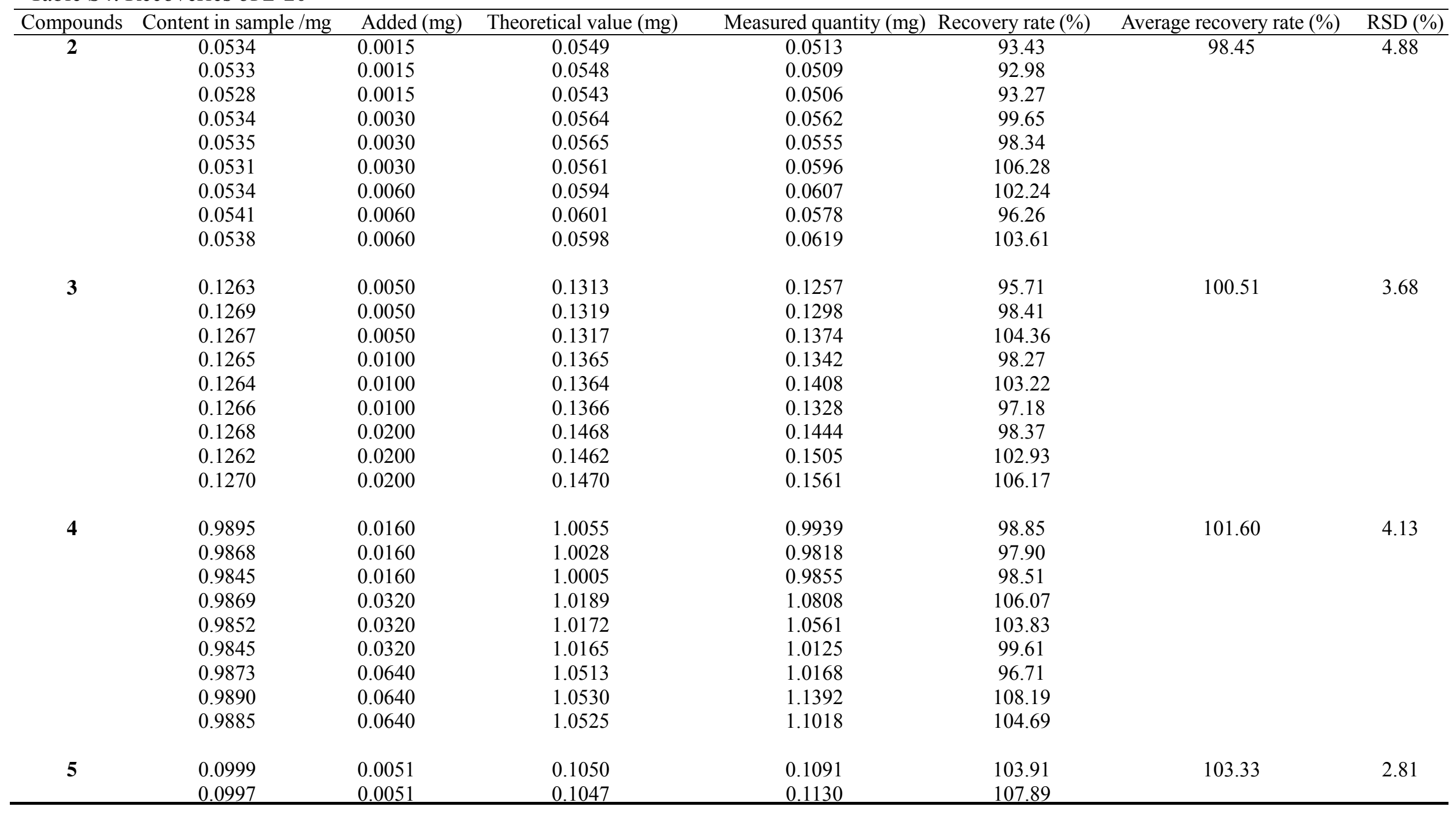




\begin{tabular}{|c|c|c|c|c|c|c|c|}
\hline & 0.0993 & 0.0051 & 0.1043 & 0.1095 & 104.94 & & \\
\hline & 0.0992 & 0.0101 & 0.1093 & 0.1163 & 106.43 & & \\
\hline & 0.0996 & 0.0101 & 0.1097 & 0.1109 & 101.10 & & \\
\hline & 0.0988 & 0.0101 & 0.1089 & 0.1077 & 98.90 & & \\
\hline & 0.0999 & 0.0202 & 0.1201 & 0.1215 & 101.17 & & \\
\hline & 0.0997 & 0.0202 & 0.1199 & 0.1236 & 103.13 & & \\
\hline & 0.0998 & 0.0202 & 0.1200 & 0.1230 & 102.50 & & \\
\hline \multirow[t]{9}{*}{6} & 0.2753 & 0.0061 & 0.2814 & 0.2807 & 99.72 & 103.02 & 3.66 \\
\hline & 0.2803 & 0.0061 & 0.2864 & 0.2800 & 97.78 & & \\
\hline & 0.2768 & 0.0061 & 0.2829 & 0.2948 & 104.20 & & \\
\hline & 0.2758 & 0.0122 & 0.2880 & 0.2966 & 102.98 & & \\
\hline & 0.2754 & 0.0122 & 0.2876 & 0.2857 & 99.33 & & \\
\hline & 0.2750 & 0.0122 & 0.2872 & 0.3148 & 109.62 & & \\
\hline & 0.2766 & 0.0244 & 0.3010 & 0.3134 & 104.14 & & \\
\hline & 0.2761 & 0.0244 & 0.3005 & 0.3107 & 103.40 & & \\
\hline & 0.2788 & 0.0244 & 0.3032 & 0.3215 & 106.03 & & \\
\hline \multirow[t]{9}{*}{7} & 0.3742 & 0.0135 & 0.3877 & 0.3972 & 102.44 & 101.42 & 3.56 \\
\hline & 0.3746 & 0.0135 & 0.3881 & 0.3695 & 95.20 & & \\
\hline & 0.3756 & 0.0135 & 0.3891 & 0.3847 & 98.87 & & \\
\hline & 0.3768 & 0.0270 & 0.4038 & 0.4022 & 99.58 & & \\
\hline & 0.3785 & 0.0270 & 0.4055 & 0.4285 & 105.67 & & \\
\hline & 0.3782 & 0.0270 & 0.4052 & 0.4174 & 103.00 & & \\
\hline & 0.3799 & 0.0540 & 0.4339 & 0.4276 & 98.54 & & \\
\hline & 0.3756 & 0.0540 & 0.4296 & 0.4472 & 104.09 & & \\
\hline & 0.3751 & 0.0540 & 0.4291 & 0.4523 & 105.40 & & \\
\hline \multirow[t]{6}{*}{8} & 0.1659 & 0.0010 & 0.1669 & 0.1585 & 94.94 & 97.79 & 3.08 \\
\hline & 0.1663 & 0.0010 & 0.1673 & 0.1581 & 94.55 & & \\
\hline & 0.1610 & 0.0010 & 0.1620 & 0.1590 & 98.15 & & \\
\hline & 0.1659 & 0.0020 & 0.1679 & 0.1562 & 93.04 & & \\
\hline & 0.1663 & 0.0020 & 0.1683 & 0.1657 & 98.47 & & \\
\hline & 0.1659 & 0.0020 & 0.1679 & 0.1650 & 98.24 & & \\
\hline
\end{tabular}




\begin{tabular}{|c|c|c|c|c|c|c|c|}
\hline & 0.1669 & 0.0040 & 0.1709 & 0.1705 & 99.73 & & \\
\hline & 0.1663 & 0.0040 & 0.1703 & 0.1707 & 100.29 & & \\
\hline & 0.1650 & 0.0040 & 0.1690 & 0.1735 & 102.67 & & \\
\hline \multirow[t]{9}{*}{9} & 0.1219 & 0.0010 & 0.1229 & 0.1208 & 98.27 & 101.06 & 4.02 \\
\hline & 0.1232 & 0.0010 & 0.1242 & 0.1220 & 98.21 & & \\
\hline & 0.1235 & 0.0010 & 0.1245 & 0.1205 & 96.76 & & \\
\hline & 0.1219 & 0.0021 & 0.1239 & 0.1349 & 108.85 & & \\
\hline & 0.1232 & 0.0021 & 0.1252 & 0.1246 & 99.50 & & \\
\hline & 0.1235 & 0.0021 & 0.1255 & 0.1224 & 97.47 & & \\
\hline & 0.1219 & 0.0041 & 0.1260 & 0.1311 & 104.03 & & \\
\hline & 0.1232 & 0.0041 & 0.1273 & 0.1307 & 102.70 & & \\
\hline & 0.1235 & 0.0041 & 0.1276 & 0.1324 & 103.74 & & \\
\hline \multirow[t]{9}{*}{10} & 0.0622 & 0.0008 & 0.0630 & 0.0603 & 95.71 & 102.35 & 3.89 \\
\hline & 0.0626 & 0.0008 & 0.0634 & 0.0672 & 105.93 & & \\
\hline & 0.0622 & 0.0008 & 0.0630 & 0.0653 & 103.61 & & \\
\hline & 0.0621 & 0.0017 & 0.0638 & 0.0629 & 98.70 & & \\
\hline & 0.0625 & 0.0017 & 0.0642 & 0.0693 & 107.94 & & \\
\hline & 0.0622 & 0.0017 & 0.0638 & 0.0631 & 98.92 & & \\
\hline & 0.0621 & 0.0033 & 0.0654 & 0.0674 & 103.04 & & \\
\hline & 0.0622 & 0.0033 & 0.0655 & 0.0687 & 104.76 & & \\
\hline & 0.0622 & 0.0033 & 0.0656 & 0.0672 & 102.57 & & \\
\hline
\end{tabular}


Table S5: The contents ${ }^{a}$ of 2-10 in BFFT and AFFT

\begin{tabular}{ccc}
\hline compounds & BFFT $(\mathrm{mg} / \mathrm{g})$ & AFFT $(\mathrm{mg} / \mathrm{g})$ \\
\hline $\mathbf{1}^{b}$ & - & - \\
$\mathbf{2}$ & $0.1996 \pm 0.0085$ & $0.2193 \pm 0.0058$ \\
$\mathbf{3}$ & $0.1784 \pm 0.0017$ & $0.1793 \pm 0.0031$ \\
$\mathbf{4}$ & $3.4575 \pm 0.0145$ & $3.2983 \pm 0.0106$ \\
$\mathbf{5}$ & $0.1395 \pm 0.0052$ & $0.1522 \pm 0.0039$ \\
$\mathbf{6}$ & $0.8128 \pm 0.0027$ & $0.7864 \pm 0.0074$ \\
$\mathbf{7}$ & $1.0438 \pm 0.0041$ & $1.0149 \pm 0.0169$ \\
$\mathbf{8}$ & $0.2511 \pm 0.0059$ & $0.2516 \pm 0.0055$ \\
$\mathbf{9}$ & $0.1089 \pm 0.0008$ & $0.0847 \pm 0.0012$ \\
$\mathbf{1 0}$ & $0.0403 \pm 0.0010$ & $0.0419 \pm 0.0013$ \\
\hline
\end{tabular}

${ }^{a}$ Mean \pm SD $(\mathrm{n}=3)$.

${ }^{b}$ Less than the quantifiable limit. 